secure high standards and improved quality of care. It is also proposed to include a non-fundholding general practitioner on the committee as it has been a policy to try to ensure that two tier service does not develop. It remains to be seen whether this is practicable. Provider units have expressed fears that fundholders might seek advantage through contracts. As the contracting process evolves individual practices might try to make their contracts more specific, but identifying patients from such practices to meet different contractual demands might prove expensive for the provider units. This should result in fundholders setting the pace and others benefiting.

A fundamental problem is funding the development of the contracting process. Operating a consortium approach will require some form of management structure among general practitioners. Yet most existing fundholders find they do not have the available money as their management fees are fully committed within their practices. One of the major trusts in
Grampian is seeking $£ 1.5 \mathrm{~m}$ to develop contract setting and monitoring and has given a contract to a firm of management consultants to handle contracting issues with fundholders. From the general practice side this matter is being urgently discussed with both the health board and management executive.

In conclusion, I hope you can see the enormous challenge fundholding is posing, and how it is an opportunity to make the health service responsive to our needs as general practitioners acting on behalf of our patients. The huge investment in computers, staff, and administration has the potential to improve the health service by making it more responsive to patients' needs and raising awareness of costs.

1 Beecham L. Harmful effects of practice budgets. $B M \mathcal{F} 1989 ; 298: 1316$

2 British Medical Association. Annual report of council 1989-90. London: BMA: 4-23.

3 Howie JGR, Heaney DJ, Maxwell M, Porter AMD, Hopton JL, Light LJ. The Scottish general practice shadow fund-holding project. Health Bulletin 1992;50(4):316-28.

\title{
The fundholding debate: should practices reconsider the decision not to fundhold?
}

\section{Duncan Keeley}

We are entering a period of deterioration in health care services. The waste and inefficiency predicted by opponents of the introduction of market mechanisms into the NHS are already becoming evident. Rapidly increasing administrative costs are contributing to reductions in service despite increased expenditure. Unrealistic assumptions are being made about the extent to which — and the speed with which - the need for hospitals can be reduced by technological advance and improvements in primary care.

For primary care the most painful consequences of the reforms stem from the cash limiting of services in the face of rising demands and costs. Cash limits will in future apply to fundholders and non-fundholders alike. The very generous terms on offer to early fundholders will not continue: the crisis in the economy and the ensuing pressure on public spending will accelerate the move to greater stringency in this area. Many fundholding practices are already making loud protest at the reduced funds on offer as regions move to more equitable methods of allocation based on capitation.

In imagining what it would be like to be fundholders in future we should assume that overall adequacy of funding for health care will be less than we have previously known. The key question is whether greater freedom to decide on the distribution of funding between drugs, staff pay, referrals, and community care will be a boon or a burden. We should consider whether taking on this role, in a context of inadequate overall expenditure, might not increase our administrative workload and the level of stress from our clinical work and adversely affect our relationships with our patients, our staff, and each other.

Many practices have so far opted not to take the inducements to fundhold, and some have invested a considerable amount of time and energy into alternative methods of organising general practitioners' input into purchasing decisions. Has the time come to change course? I think not: these are the reasons why.

Thame, Oxfordshire OX9 3JZ

Duncan Keeley, general

practitioner

$B M \mathcal{F} 1993 ; 306: 697-8$

\section{Reasons for not fundholding}

(1) Greatly increased administrative workload-Even with the existing generous management and computer- isation allowances, fundholding involves general practitioners in considerable extra administrative work, over and above that already entailed by the new contract. With an extension of the services covered by the fund, and a reduction in management allowances as more practices take funds, this additional workload will increase and the rewards will dwindle. Few of us truly enjoy administrative work, and the time that we spend on it is lost from direct contact with our patients -or our families.

(2) Conflict with the general practitioner's role as the patient's advocate-Fundholding gives general practitioners an explicit and visible responsibility for rationing the health services made available to their own patients. This conflict of interest may undermine our patients' trust that our decisions on whether or not to treat, investigate, or refer are based solely on their needs rather than on what the fund can afford. Such distrust may extend to the suspicion that our decisions may be influenced by personal financial self interest. This perception, however unfounded it may be, has the potential to complicate many consultations every working day of our lives. The more inadequate that overall funding of services becomes, the more this problem will become a reality. For patients, continued trust in the basis for their doctor's decisions is worth more than the possibility of quicker access to elective surgery. The fact that we already participate in certain ways in what are effectively rationing decisions does not constitute an argument for greatly increasing the scope and visibility of that role.

(3) Implicit acceptance of responsibility for providing a wide range of services to our patients-In taking a fund we accept responsibility for purchasing hospital services, drugs, and now community care on behalf of our patients. As the services provided become less adequate we will find that the perceived responsibility for these inadequacies will also be laid at our door. Government will be very keen to do this, just as governors will be blamed for poor schools, local authorities for poor local public services, and so on. A key theme of policy in recent years has been to maximise the extent to which other agencies than government itself can be held responsible for inadequacies in public sector services. We would be most 
unwise to take on this role in the current economic climate.

(4) Boosting private health care-It is no coincidence that the services covered originally by the fund were those which the private health sector could compete with the NHS to provide-often on favourable if unfair terms. Holding a fund would give us a clear and continuing incentive to maximise the extent to which our patients took out and used private health insurance. The concept of fundholding was undoubtedly designed with this in mind. Do we want to be a party to further undermining the NHS in this way?

(5) Weakened district planning of health servicesDistrict health authorities have to plan health services for populations, maximise efficiency in the use of resources, and address inequalities in provision. The more that their budget is diverted to fundholding practices, the more their capacity to do so will be undermined, to the detriment of important areas of service for all patients. It may be argued that fundholding allows us to discharge these responsibilities ourselves in respect of our own practice population, and that we are capable of doing the job better than a large purchasing authority. I would suggest that this is not so. Few of us have the time, training, or expertise to do this job properly, even if it were possible to do it for a population as small as 10000 people-which it is not. Some general practitioners are developing a high degree of expertise in purchasing: their skills would be better used in providing properly supported and remunerated guidance to purchasers at district level.

(6) Greater threat, in the medium to long term, to the independence and identity of practices-This may seem an odd assertion. Many practices are worried that only by taking a fund can they retain some independence from what they fear may be increasingly arbitrary or incompetent control by the family health services authority or its eventual successor. But there is a serious question mark over whether fundholding at the level of single practices will remain viable. With greater financial stringency there will be increasing pressure for economies of scale by the amalgamation of fundholding practices. This would lead to a greater loss of independence and the identity of the practice than is likely to occur by staying outside the fundholding system. General practices would evolve into Americanstyle health maintenance organisations-a prospect perhaps more appealing to planners than to patients or general practitioners.

\section{Conclusion}

The reasons I have cited make a largely self interested case for not fundholding. There is a further reason that operates more at the level of values. Fundholding poses ethical problems, either because it secures a better service for the patients of a fundholding practice over those whose doctors happen not to hold a fund, or because it does not. If not, it is an appalling waste of time and money that would be better spent on other things. In some districts the management costs of fundholding already exceed the cost of running the family health services authority.

We are seeing the beginnings of a two tier system. Hospitals openly confess to giving higher priority to fundholders' patients as they try to avoid financial crisis. District health authority contracts fail to cover hospitals' existing work rate. As the perennial overspend on core and emergency services (used by the patients of fundholders and non-fundholders alike) leads hospitals to restrict their activities, fundholders' patients are getting preferential access to elective surgery. Should we accept the inevitability and permanence of this state of affairs? Must we take a fund so as to avoid having our patients condemned to the lower tier of a two tier service?

Politicians and health service managers have repeatedly assured us that a two tier service is not on the agenda. We should take them at their word and hold them to it, rather than resign ourselves to the judgment that they have been lying. Not to do so would be a betrayal of our hope that the founding principles of the National Health Service can survive the government's reforms. Non-fundholding practices must continue to secure equivalent access to funding for staff, premises, and equipment and equitable treatment for their patients. If enough practices stay out of fundholding then a more rational and cost effective embodiment of the purchaser-provider split will emerge from the present chaos.

I am grateful to my partners Ken Burch, Andrew Farmer, Richard Harrington, Andrew and Pat Markus, and Blue Tewson for lively discussions born of varying degrees of agreement and disagreement with the views expressed here, which are my own.

\section{A PATIENT WHO CHANGED MY PRACTICE}

\section{On the wrong track}

Ethel, an old lady of 93 , lived alone in a block of service flats. Although frail, she was fit despite her age and we rarely saw her. One day she asked for a visit, complaining of feeling sick and burning when she passed urine. I sent off a mid-stream urine sample and gave her a three day course of co-trimoxazole without waiting for the result. This confirmed a urinary tract infection with a sensitive organism. When I rang her two days later she felt much better.

I was surprised to get a further call the next week to say that she felt unwell again. There was nothing specific on clinical examination, but this time I took a full blood count and erythrocyte sedimentation rate, fearing some systemic illness, possibly a malignancy. I was horrified when I received a call from the laboratory to tell me that she had pancytopenia, with low white cell and platelet counts. I had almost certainly precipitated this with my treatment for her urinary infection.
The haemotologist advised a "folinic acid rescue" similar to that given to oncology patients. I obtained folinic acid from the hospital pharmacy and visited her three days running to give her the injections, as well as starting her on folic acid. After a few days her haematological indices improved, and she felt better. Unfortunately, she died shortly afterwards, but I am relieved to say that the cause seemed to be unrelated.

Elderly housebound people are often short of vitamins such as folate. I never use folate antagonist antibiotics in patients over 70 now, and I am much more aware of other vitamin deficiency problems such as calcium and vitamin D.-PETER D TOON is a general practitioner in London

We welcome contributions to fillers up to 600 words: $A$ patient who changed my practice; $A$ paper that changed my practice; A memorable patient; The message I would most like to leave behind, or similar topics. 